\title{
Oxidative Cleavage of $\beta$-Lactam Ring of Cephalosporins with Chloramine-T in Alkaline Medium: A Kinetic, Mechanistic, and Reactivity Study
}

\author{
Anu Sukhdev, A. S. Manjunatha, and Puttaswamy Puttaswamy \\ Department of Post-Graduate Studies in Chemistry, Bangalore University, Central College Campus, \\ Bangalore Karnataka 560 001, India \\ Correspondence should be addressed to Puttaswamy Puttaswamy; pswamy_chem@yahoo.com
}

Received 21 February 2013; Accepted 28 March 2013

Academic Editors: I. Anusiewicz, J. M. Farrar, and E. B. Starikov

Copyright (C) 2013 Anu Sukhdev et al. This is an open access article distributed under the Creative Commons Attribution License, which permits unrestricted use, distribution, and reproduction in any medium, provided the original work is properly cited.

\begin{abstract}
Cephalosporins are $\beta$-lactam antibiotics, and the important drugs of this group are cephalexin, cefadroxil and cephradine. In the present research, the kinetics and mechanism of oxidation of cephalexin (CEX), cefadroxil (CFL), and cephradine (CPD) with chloramine-T (CAT) in alkaline medium were investigated at $301 \mathrm{~K}$. All the three oxidation reactions follow identical kinetics with a first-order dependence each on $[\mathrm{CAT}]_{\circ}$ and [substrate $]_{0}$. The reaction is catalyzed by hydroxide ions, and the order is found to be fractional. The dielectric effect is negative. Proton inventory studies in $\mathrm{H}_{2} \mathrm{O}-\mathrm{D}_{2} \mathrm{O}$ mixtures with CEX as a probe have been made. Activation parameters and reaction constants have been evaluated. Oxidation products were identified by mass spectral analysis. An isokinetic relation was observed with $\beta=378 \mathrm{~K}$, indicating that enthalpy factors control the rate. The rate increases in the following order: $\mathrm{CPD}>\mathrm{CFL}>\mathrm{CEX}$. The proposed mechanism and the derived rate law are consistent with the observed kinetics.
\end{abstract}

\section{Introduction}

Cephalosporins are an important and large class of bactericidal antimicrobial agents [1]. These are semisynthetic antibiotics that contain a $\beta$-lactam ring which is fused to a dihydrothiazine moiety. Cephalexin [(2-[[2-amino-2(phenylacetyl)-acetamido]-3-methyl-8-oxo-5-thia-lazabicyclo[4.2.0] oct-2-ene-2-carboxylic acid)], cefadroxil [(2-[2amino-2-(4-hydroxyphenyl)-acetamido]-3-methyl-8-oxo-5thia-1-azabicyclo[4.2.0]oct-2-ene-2-carboxylicacid), and cephradine [(2-[2-amino-2-(cyclohexa-1,4-dienyl)acetamido]-3-methyl-8-oxo-5-thia-lazabicyclo[4.2.0] oct-2-ene-2carboxylic acid] are important cephalosporins. These are widely used antibiotics which differ from each other with diverse group of substituents, namely, phenyl, hydroxyphenyl, and cyclohexadienyl, at the 7th position of the cephem ring. These drugs are widely used to treat respiratory and urinary tract infections, bronchitis, pneumonia, prostatitis, and soft tissues infections that are often caused by sensitive bacteria [2, 3]. From the literature survey, it is evident that a lot of attention has been paid on the analytical methods for the determination of these drugs with various reagents $[4,5]$. But no information is available on the oxidation of these drugs with any reagent from the kinetic and mechanistic aspects. It is also noted that despite the importance of these drugs, relatively little is known about their mode of action at the molecular level. Therefore, the mechanism and rate law of these drugs are obscure. The oxidation-kinetic studies of these drugs provide much information about their mechanistic chemistry.

Sodium N-chloro-p-toluenesulfonamide ( $\mathrm{p}-\mathrm{CH}_{3} \mathrm{C}_{6} \mathrm{H}_{4}$ $\mathrm{SO}_{2} \mathrm{NClNa} \cdot 3 \mathrm{H}_{2} \mathrm{O}$ ), commonly known as chloramine-T (CAT) is of great interest due to its diverse behaviour. The versatile nature of CAT is due to its ability to act as sources of halonium cations, hypohalite species, and nitrogen anions which act both as bases and nucleophiles [6]. It is a potent oxidizing and chlorinating agent in both acidic and alkaline media, with a two electron change per mole, giving p-toluenesulfonamide (PTS) and $\mathrm{NaCl}$. The oxidation potential of PTS/sulfonamide system is $\mathrm{pH}$ dependent [7], and it decreases with the increase in $\mathrm{pH}$ of the medium $(1.139,0.778$, and $0.614 \mathrm{~V}$ at $\mathrm{pH} 0.65,7.0$, and 9.7, resp.). 
CAT is commercially available, inexpensive, water-tolerant, nontoxic, and easy to handle [8]. Mechanistic aspects of many of its reactions have been well documented [8-12].

In the light of the above information and in continuation with our ongoing research on the oxidation kinetics and mechanism of important organic substrates [13-15], we report here the results obtained on the oxidation kinetics of three cephalosporin drugs, namely, cephalexin (CEX), cefadroxil (CFL), and cephradine (CPD) with CAT in alkaline medium in order to elucidate the mechanism of these redox systems and also to assess their relative rates. The studies were extended to deduce the appropriate kinetic rate law and also to establish the isokinetic relationship through the computed thermodynamic parameters.

\section{Experimental}

2.1. Reagents. The substrates cephalexin, cefadroxil, and cephradine were of analytical grade of purity and were gifted by Orchid Chemicals Pvt. Ltd., Chennai, India. These drugs were used as received. Fresh aqueous solutions of substrates were prepared whenever required. Chloramine T (Merck) was purified by the method of Carrell Morris et al. [16]. An aqueous solution of CAT was prepared, standardized iodometrically and stored in amber-colored, stoppered bottles until further use. The concentrations of stock solutions were periodically checked. All other reagents were of accepted grades of purity. Heavy water $\left(\mathrm{D}_{2} \mathrm{O} 99.4 \%\right)$ was supplied by BARC, Mumbai, India, and was used to investigate the solvent isotope effect. Double distilled water was used throughout the work. The regression coefficient $R^{2}$ was calculated using $\mathrm{fx}$ $100 Z$ scientific calculator.

2.2. Kinetic Measurements. All the kinetic runs were performed under pseudo-first-order conditions with a known excess of $[\text { substrate }]_{0}$ over [oxidant $]_{0}$. The reactions were carried out in glass stoppered Pyrex boiling tubes whose outer surface was coated black to eliminate photochemical effects. Appropriate amounts of the substrate and $\mathrm{NaOH}$ solutions and water (to maintain a constant total $50 \mathrm{~mL}$ volume) were taken in the tube and thermostated at $301 \mathrm{~K}$ for thermal equilibrium. A known amount of CAT solution also thermostated at the same temperature was rapidly added to the mixture in the boiling tube. The mixture was periodically shaken to ensure uniform concentration, and the progress of the reaction was monitored by iodometric determination of unreacted CAT in a measured aliquot ( $5 \mathrm{~mL}$ each) of the reaction mixture at different intervals of time. The course of the reaction was studied for more than two half-lives. The pseudo first-order rate constants $\left(k^{\prime} \mathrm{s}^{-1}\right)$, calculated from linear plots of $\log [\mathrm{CAT}]$ versus time, were reproducible within $2-6 \%$.

2.3. Reaction Stoichiometry and Product Analysis. Different aliquots of reaction mixtures containing different concentrations of CAT and substrate with constant $\mathrm{NaOH}$ concentration $\left(4.4 \times 10^{-3} \mathrm{~mol} \mathrm{dm}^{-3}\right)$ were equilibrated at $301 \mathrm{~K}$ for $24 \mathrm{~h}$. Iodometric titration of unreacted CAT in the reaction

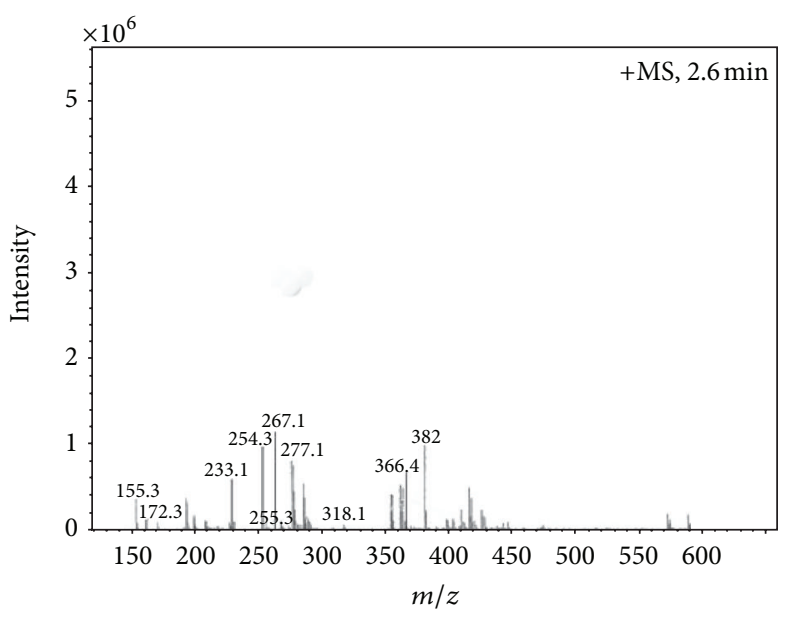

FIGURE 1: Mass spectrum of 2\{[2-amino-2-(phenyl)-acetylamino]carboxy-methyl\}-5-methyl-1-oxo-1,2,3,6-tetrahydro- $1 \lambda$-4-[1,3]thiazine-4-carboxylic acid with its parent molecular ion peak at mass/charge at $382.0 \mathrm{amu}$.

mixtures showed that one mole of each substrate consumed two moles of the oxidant, and the stoichiometry is given in Figure 6 .

The reactions in case of all the three substrates with CAT, separately in the stoichiometric ratio under stirred conditions in presence of $\mathrm{NaOH}\left(4.4 \times 10^{-3} \mathrm{~mol} \mathrm{dm}^{-3}\right)$, were allowed to progress for $24 \mathrm{~h}$ at $301 \mathrm{~K}$. The progress of the reaction was monitored by TLC. After completion of the reactions, the products were neutralized with $\mathrm{HCl}$. The solid product formed is filtered off and washed thoroughly with water and dried over sodium sulphate. The organic products were subjected to mass spectral analysis. The molecular ion peaks at 382.0 (Figure 1), 398.4 (Figure 2), and $384.5 \mathrm{amu}$ (Figure 3) clearly confirms 2-\{[2-amino-2-(phenyl)-acetylamino $]$ carboxy-methyl $\}$-5-methyl-1-oxo-1,2,3,6-tetrahydro- $1 \lambda$-4$[1,3]$ thiazine-4-carboxylicacid, 2-\{[2-Amino-2-(4-hydroxyphenyl)-acetylamino]-carboxy-methyl\}-5-methyl-1-oxo-1,2, 3,6-tetrahydro- $1 \lambda$-4-[1,3]thiazine-4-carboxylic acid, and 2Amino-2-(cyclohexane-1,4-diene)-acetylamino]-carboxymethyl\}-5-methyl-1-oxo-1,2,3,6-tetrahydro- $1 \lambda$-4-[1,3]thiazine-4-carboxylic acid as the oxidation products of CEX, $\mathrm{CFD}$, and CPD, respectively.

p-Toluenesulfonamide among the reaction product was extracted with ethyl acetate. It was detected by paper chromatography [13]. Benzyl alcohol saturated with water was used as the solvent with $0.5 \%$ vanillin in $1 \% \mathrm{HCl}$ solution in ethanol as spray reagent $\left(R_{f}=0.905\right)$. It was also noted that no further oxidation of these products, under prevailing experimental conditions.

\section{Results and Discussion}

Our preliminary experimental studies revealed that the oxidation reactions of CEX, CFL, and CPD with CAT were facile in alkaline medium. Therefore, the oxidation of CEX, CFL 


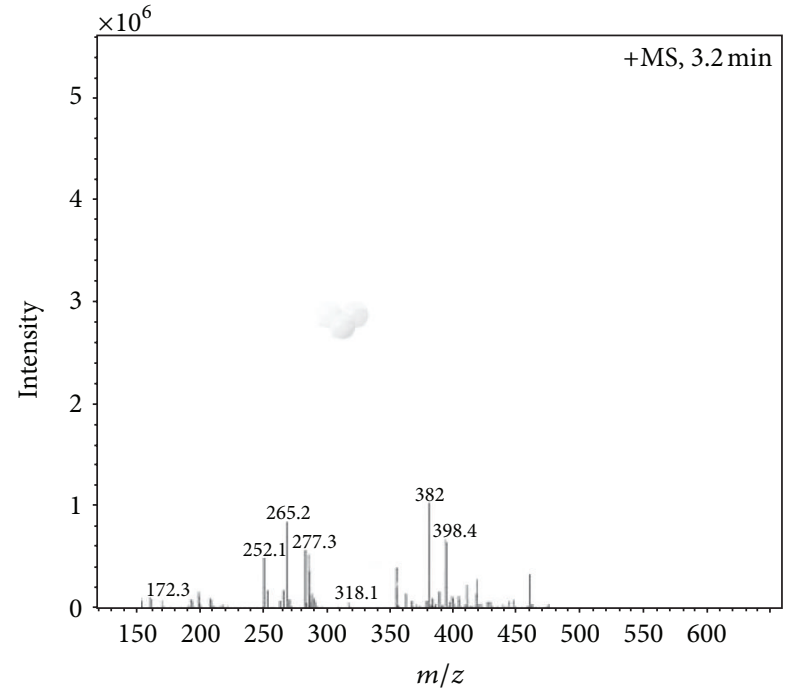

Figure 2: Mass spectrum of 2-\{[2-amino-2-(4-hydroxy-phenyl)acetylamino]-carboxy-methyl\}-5-methyl-1-oxo-1,2,3,6-tetrahydro$1 \lambda$-4-[1,3]thiazine-4-carboxylic acid with its parent molecular ion peak at mass/charge at $398.4 \mathrm{amu}$.

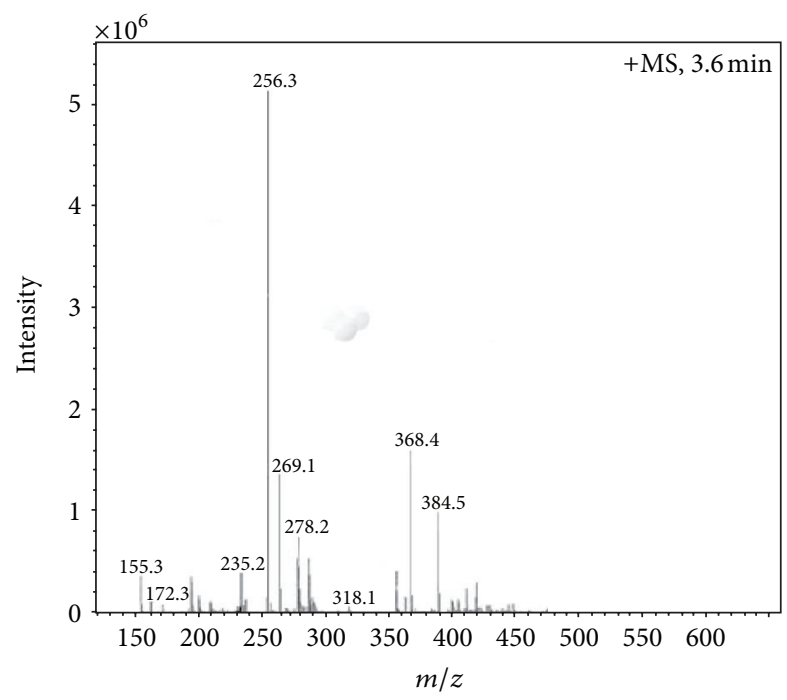

FIgURE 3: Mass Mass spectrum of 2-\{2-amino-2-(cyclohexane1,4-diene)-acetylamino]-carboxy-methyl $\}$-5-methyl-1-oxo-1,2,3,6tetrahydro-1 $\lambda-4-[1,3]$ thiazine-4-carboxylic acid with its parent molecular ion peak at mass/charge at $384.5 \mathrm{amu}$.

and CPD with CAT was kinetically investigated under pseudo first-order conditions with large excess of the substrate over oxidant at $301 \mathrm{~K}$ in $\mathrm{NaOH}$ medium. The same oxidationkinetic behaviour was observed for all the three substrates which are under the present study.

3.1. Effect of Reactant Concentrations on the Rate of Reaction. When the substrate is in large excess over oxidant at constant [substrate $]_{\mathrm{o}},[\mathrm{NaOH}]$, and temperature, plots of $\log [\mathrm{CAT}]$ versus time are linear $\left(R^{2}>0.9873\right)$ for all three substrates, indicating a first-order dependence of rate on $[\mathrm{CAT}]_{0}$. The pseudo first-order rate constants $\left(k^{\prime} \mathrm{s}^{-1}\right)$ calculated are almost constant at different initial concentrations of CAT (Table 1). Hence, the rate of disappearance of CAT follows first-order kinetics. It is seen from Table 1 that the value of $k^{\prime}$ increases with the increase in concentration of the substrate, and plots of $\log k^{\prime}$ versus $\log$ [substrate] are linear $\left(R^{2}>0.9999\right)$ with unit slopes. Hence, the reaction is also of first-order with respect to [substrate $]_{0}$. Further, plots of $k^{\prime}$ versus [substrate $]_{0}$ are linear $\left(R^{2}>0.9998\right)$ passing through origin, confirming the first-order dependence on [substrate $]_{0}$ and also show that the substrate, CAT complex, has only transient existence. Furthermore, second-order rate constants were calculated using the equation $k^{\prime \prime}=k^{\prime} /[\text { substrate }]_{\mathrm{o}}$ and were reported in Table 1 . The values of $k^{\prime \prime}$ are nearly the same for all the three drugs, establishing the first-order dependence of rate on $[\text { substrate }]_{0}$.

3.2. Effect of Alkali Concentration on the Rate of Reaction. At constant $[\mathrm{CAT}]_{\mathrm{o}}$ and $[\text { substrate }]_{\mathrm{o}}$, values of $k^{\prime}$ increased with the increase in $[\mathrm{NaOH}]$ (Table 1). This clearly indicates that the reaction is catalyzed by $\mathrm{OH}^{-}$ions. Further, plots of $\log k^{\prime}$ versus $\log [\mathrm{NaOH}]$ were linear $\left(R^{2}>0.9984\right)$ with slopes of $0.53,0.44$, and 0.33 for CEX, CFL, and CPD, respectively, suggesting a fractional-order dependence of rate on $\left[\mathrm{OH}^{-}\right]$ in all the three cases.

\subsection{Effect of p-Toluenesulfonamide (PTS) Concentration on the} Rate of Reaction. Addition of the reduction product of CAT, p-toluenesulfonamide $\left(2.0 \times 10^{-3} \mathrm{~mol} \mathrm{dm}^{-3}\right)$, does not have any pronounced effect on the rate of the reaction, indicating that it is not involved in the preequilibrium with the oxidant.

3.4. Effect of Halide Ions on the Rate of Reaction. Addition of $\mathrm{Cl}^{-}$or $\mathrm{Br}^{-}$ions as $\mathrm{NaCl}$ or $\mathrm{NaBr}\left(5.0 \times 10^{-3} \mathrm{~mol} \mathrm{dm}^{-3}\right)$ had no effect on the rate, signifying that no interhalogen or free chlorine is formed in the reaction sequence.

3.5. Effect of Ionic Strength of the Medium on the Rate of Reaction. The effect of ionic strength of the medium on the rate of reaction was carried out at $0.30 \mathrm{~mol} \mathrm{dm}^{-3}$ using $\mathrm{NaClO}_{4}$ solution, with all other experimental conditions held constant. It was found that the added $\mathrm{NaClO}_{4}$ had negligible effect on the reaction rate, suggesting that a neutral molecule is involved in the rate-determining step. Subsequently, the ionic strength of the reaction mixture was not kept constant for kinetic runs.

3.6. Effect of Dielectric Constant of the Medium on the Rate of Reaction. Rate studies were made in $\mathrm{H}_{2} \mathrm{O}-\mathrm{MeOH}$ mixtures at different compositions $(0-30 \% \mathrm{v} / \mathrm{v})$ in order to study the effect of varying dielectric constant $(D)$ of the solvent medium, with all other experimental conditions being held constant. The rate was found to decrease with the increase in $\mathrm{MeOH}$ content (Table 2) in all the three substrates, and 
plots of $\log k^{\prime}$ versus $1 / D$ were linear $\left(R^{2}>0.9892\right)$ with negative slopes. The values of dielectric constant of $\mathrm{H}_{2} \mathrm{O}$ $\mathrm{MeOH}$ mixtures reported in the literature [17] were used. It was further noticed that no reaction of the dielectric with the oxidant under the experimental conditions was employed.

3.7. Effect of Solvent Isotope on the Rate of Reaction. As the oxidation of cephalosporins by CAT was accelerated by hydroxyl ion concentration, the solvent isotope effect was studied in $\mathrm{D}_{2} \mathrm{O}$ medium with $\mathrm{CEX}$ as a probe. Values of $k^{\prime}\left(\mathrm{H}_{2} \mathrm{O}\right)$ and $k^{\prime}\left(\mathrm{D}_{2} \mathrm{O}\right)$ were $2.31 \times 10^{-4} \mathrm{~s}^{-1}$ and $4.45 \times$ $10^{-4} \mathrm{~s}^{-1}$, giving a solvent isotope effect $k^{\prime}\left(\mathrm{H}_{2} \mathrm{O}\right) / k^{\prime}\left(\mathrm{D}_{2} \mathrm{O}\right)$ $=0.52$. Proton inventory studies were made in $\mathrm{H}_{2} \mathrm{O}-\mathrm{D}_{2} \mathrm{O}$ mixtures containing different atom fractions of deuterium $(n)$, the results of which are shown in Table 3.

3.8. Effect of Temperature on the Rate of Reaction. The reaction rates were determined at different temperatures (291-306 K), keeping the other experimental conditions the same. Based on the Arrhenius plots of $\log k^{\prime}$ versus $1 / T$ $\left(R^{2}>0.9985\right)$, activation energy and other thermodynamic parameters $\left(\Delta H^{\#}, \Delta G^{\#}, \Delta S^{\#}\right.$, and $\left.\log A\right)$ were computed for all the three substrates. All these results are summarized in Table 4 .

3.9. Free Radical Test. To test for free radical species in the reaction mixture, it was added to acrylamide. Polymerization did not occur, confirming the absence of free radical species in the reaction mixture. Appropriate control experiments were also run simultaneously.

3.10. Reactive Species of CAT. Chloramine-T (TsNClNa) is a moderately strong electrolyte [6] in aqueous solutions. $\left(\mathrm{TsNClNa} \rightleftharpoons \mathrm{TsN}^{-} \mathrm{Cl}+\mathrm{Na}^{+}\right.$). The possible oxidizing species of CAT in acid medium $[6,18-20]$ are $\mathrm{TsNHCl}$, $\mathrm{TsNCl}_{2}$, $\mathrm{HOCl}$, and possibly $\mathrm{H}_{2} \mathrm{O}^{+} \mathrm{Cl}$. In aqueous alkaline solutions of $\mathrm{CAT}, \mathrm{TsNCl}_{2}$ does not exist, and the expected reactive species are $\mathrm{TsN}^{-} \mathrm{Cl}$, $\mathrm{TsNHCl}, \mathrm{OCl}^{-}$, and $\mathrm{HOCl}$ as shown by

$$
\begin{aligned}
\mathrm{TsN}^{-} \mathrm{Cl}+\mathrm{H}_{2} \mathrm{O} & \rightleftharpoons \mathrm{TsNHCl}+\mathrm{OH}^{-} \\
\mathrm{TsNHCl}+\mathrm{OH}^{-} & \rightleftharpoons \mathrm{TsNH}_{2}+\mathrm{OCl}^{-} \\
\mathrm{TsNHCl}+\mathrm{H}_{2} \mathrm{O} & \rightleftharpoons \mathrm{TsNH}_{2}+\mathrm{HOCl} .
\end{aligned}
$$

If TsNHCl is the reactive species, retardation of rate by $\mathrm{OH}^{-}$would be expected according to (1), which is contrary to the experimental results. The absence of any significant effect of the added p-toluenesulfonamide on the rate rules out the involvement of $\mathrm{OCl}^{-}$and $\mathrm{HOCl}$ ions in the reaction sequence ((2) and (3)). Further, Bishop and Jennings [6] have calculated the order of the concentrations of the various species present at different $\mathrm{pH}$ in $0.05 \mathrm{~mol} \mathrm{dm}^{-3}$ solution of CAT, and a comparison with the concentration of species present in alkaline CAT solution would indicate that $\mathrm{TsN}^{-} \mathrm{Cl}$ is the likely oxidizing species. In the present study, the positive effect of $\left[\mathrm{OH}^{-}\right]$reveals that the anion $\mathrm{TsN}^{-} \mathrm{Cl}$ is the most probable oxidizing species.

$$
\begin{aligned}
& \mathrm{TsNHCl}+\mathrm{OH}^{-} \rightleftharpoons K_{1} \rightleftharpoons \mathrm{TsN}^{-} \mathrm{Cl}+\mathrm{H}_{2} \mathrm{O} \quad \text { (i) Fast } \\
& \mathrm{TsN}^{-} \mathrm{Cl}+\mathrm{S} \stackrel{K_{2}}{\longrightarrow} \text { Complex } \quad \text { (ii) Slow and rds } \\
& \text { Complex }+\mathrm{TsN}^{-} \mathrm{Cl} \stackrel{K_{3}}{\longrightarrow} \text { Products } \quad \text { (iii) Fast }
\end{aligned}
$$

Scheme 1: A general scheme for the oxidation of cephalosporins with CAT in alkaline medium.

Bearing the above facts in mind, the following mechanism (Scheme 1) is proposed for the oxidation of cephalosporins by CAT in alkaline medium.

Here, $S$ is the substrate, and the structure of the intermediate complex species is depicted in Scheme 2 where a detailed mechanistic interpretation for the oxidation of cephalosporins by CAT in alkaline medium is illustrated. In step (i) of Scheme 2, the conjugate acid $\mathrm{TsNHCl}$ reacts with $\mathrm{OH}^{-}$in an alkali accelerating step to form an anion $\mathrm{TsN}^{-} \mathrm{Cl}$. In the next slow and rds (Step (ii)), the lone pair of electrons on sulphur atom of the substrate interacts with positive chlorine of the oxidant species to form a complex intermediate species with the removal of $\mathrm{TsNH}_{2}$. In the next subsequent fast steps, this complex intermediate species reacts with another mole of oxidant leading to the cleavage of lactam ring and yields the ultimate products with the elimination of a molecule of $\mathrm{HCl}$.

3.11. Kinetic Rate Law. From slow/rate-determining step (Step (ii)) of Scheme 1,

$$
\text { Rate }=k_{2}\left[\mathrm{TsN}^{-} \mathrm{Cl}\right][\mathrm{S}] .
$$

If $[\mathrm{CAT}]_{\mathrm{t}}$ represents the total effective concentration of CAT in solution, then

$$
[\mathrm{CAT}]_{\mathrm{t}}=[\mathrm{TsNHCl}]+\left[\mathrm{TsN}^{-} \mathrm{Cl}\right] .
$$

From Step (i) of Scheme 1,

$$
K_{1}=\frac{\left[\mathrm{TsN}^{-} \mathrm{Cl}\right]\left[\mathrm{H}_{2} \mathrm{O}\right]}{[\mathrm{TsNHCl}]\left[\mathrm{OH}^{-}\right]}
$$

or

$$
[\mathrm{TsNHCl}]=\frac{\left[\mathrm{TsN}^{-} \mathrm{Cl}\right]\left[\mathrm{H}_{2} \mathrm{O}\right]}{K_{1}\left[\mathrm{OH}^{-}\right]} .
$$

By substituting for [ $\mathrm{TsNHCl}$ from (7) into (5) and solving for $\left[\mathrm{TsN}^{-} \mathrm{Cl}\right]$, we get

$$
\left[\mathrm{TsN}^{-} \mathrm{Cl}\right]=\frac{[\mathrm{CAT}]_{\mathrm{t}}\left[\mathrm{OH}^{-}\right]}{\left[\mathrm{H}_{2} \mathrm{O}\right]+K_{1}\left[\mathrm{OH}^{-}\right]} .
$$

By substituting for $\left[\mathrm{TsN}^{-} \mathrm{Cl}\right]$ from (8) into (4), the following rate law (9) is obtained:

$$
\text { Rate }=\frac{K_{1} k_{2}[\mathrm{CAT}]_{t}[\mathrm{~S}]\left[\mathrm{OH}^{-}\right]}{\left[\mathrm{H}_{2} \mathrm{O}\right]+K_{1}\left[\mathrm{OH}^{-}\right]}
$$


TABLE 1: Effect of varying concentrations of oxidant, substrate, and alkali on the rate of reaction at $301 \mathrm{~K}$.

\begin{tabular}{|c|c|c|c|c|c|}
\hline \multirow{2}{*}{$\begin{array}{l}10^{4}[\mathrm{CAT}]_{\mathrm{o}} \\
\left(\mathrm{mol} \mathrm{dm}^{-3}\right)\end{array}$} & \multirow{2}{*}{$\begin{array}{c}10^{3}[\text { Substrate }]_{\mathrm{o}} \\
\left(\mathrm{mol} \mathrm{dm}^{-3}\right)\end{array}$} & \multirow{2}{*}{$\begin{array}{r}10^{3}[\mathrm{NaOH}] \\
\left(\mathrm{mol} \mathrm{dm}^{-3}\right)\end{array}$} & \multicolumn{3}{|c|}{$10^{4} k^{\prime}\left(\mathrm{s}^{-1}\right)$} \\
\hline & & & CEX & CFL & CPD \\
\hline 0.4 & 1.0 & 4.4 & 2.25 & 5.24 & 9.78 \\
\hline 1.0 & 1.0 & 4.4 & 2.28 & 5.10 & 9.69 \\
\hline 2.0 & 1.0 & 4.4 & 2.31 & 5.15 & 9.84 \\
\hline 4.0 & 1.0 & 4.4 & 2.34 & 5.21 & 9.85 \\
\hline 10.0 & 1.0 & 4.4 & 2.29 & 5.18 & 9.80 \\
\hline 2.0 & 0.25 & 4.4 & $0.65(2.60)$ & $1.34(5.36)$ & $2.50(10.0)$ \\
\hline 2.0 & 0.5 & 4.4 & $1.22(2.40)$ & $2.63(5.26)$ & $4.94(9.88)$ \\
\hline 2.0 & 1.0 & 4.4 & $2.31(2.31)$ & $5.15(5.15)$ & $9.84(9.84)$ \\
\hline 2.0 & 2.0 & 4.4 & $4.95(2.48)$ & $10.5(5.25)$ & $19.2(9.60)$ \\
\hline 2.0 & 4.0 & 4.4 & $9.81(2.45)$ & $20.3(5.08)$ & $38.4(9.60)$ \\
\hline 2.0 & 1.0 & 2.2 & 1.65 & 3.64 & 6.65 \\
\hline 2.0 & 1.0 & 4.4 & 2.31 & 5.15 & 9.84 \\
\hline 2.0 & 1.0 & 6.6 & 3.35 & 6.10 & 13.4 \\
\hline 2.0 & 1.0 & 8.8 & 4.75 & 7.67 & 15.5 \\
\hline 2.0 & 1.0 & 10.0 & 7.22 & 8.96 & 21.1 \\
\hline
\end{tabular}

The values in parentheses refer to second-order rate constants $\left(k^{\prime \prime} \mathrm{dm}^{3} \mathrm{~mol}^{-1} \mathrm{~s}^{-1}\right)$.

TABLE 2: Effect of varying dielectric constant $(D)$ of the medium on the rate of reaction at $301 \mathrm{~K}$.

\begin{tabular}{lcccc}
\hline$\% \mathrm{MeOH}(\mathrm{v} / \mathrm{v})$ & $\mathrm{N}$ & \multicolumn{3}{c}{$10^{4} k^{\prime}\left(\mathrm{s}^{-1}\right)$} \\
\hline 0 & & $\mathrm{CEX}$ & $\mathrm{CFL}$ & $\mathrm{CPD}$ \\
10 & 76.73 & 2.31 & 5.15 & 9.84 \\
20 & 72.37 & 1.84 & 4.76 & 8.45 \\
30 & 67.48 & 1.65 & 3.98 & 7.62 \\
\hline
\end{tabular}

Experimental conditions: $[\mathrm{CAT}]_{0}=2.0 \times 10^{-4} \mathrm{~mol} \mathrm{dm}^{-3} ;[\text { Substrate }]_{\mathrm{o}}=$ $1.0 \times 10^{-3} \mathrm{~mol} \mathrm{dm}^{-3}$; and $[\mathrm{NaOH}]=4.4 \times 10^{-3} \mathrm{~mol} \mathrm{dm}^{-3}$.

TABle 3: Proton inventory studies for cephalexin in $\mathrm{H}_{2} \mathrm{O}-\mathrm{D}_{2} \mathrm{O}$ mixtures at $301 \mathrm{~K}$

\begin{tabular}{lccc}
\hline $\begin{array}{l}\mathrm{H}_{2} \mathrm{O}-\mathrm{D}_{2} \mathrm{O} \\
\text { mixtures }(\mathrm{v} / \mathrm{v})\end{array}$ & $\begin{array}{c}\text { Atom fraction of } \\
\text { deuterium }(n)\end{array}$ & $k^{\prime} 10^{4}\left(\mathrm{~s}^{-1}\right)$ & $\left(k_{o}^{\prime} / k_{n}^{\prime}\right)^{1 / 2}$ \\
\hline 0 & 0.000 & 2.31 & 1.0000 \\
25 & 0.248 & 2.75 & 0.9165 \\
50 & 0.497 & 3.32 & 0.8341 \\
75 & 0.745 & 3.86 & 0.7736 \\
100 & 0.994 & 4.45 & 0.7205 \\
\hline
\end{tabular}

Experimental conditions: $[\mathrm{CAT}]_{\mathrm{o}}=2.0 \times 10^{-4} \mathrm{~mol} \mathrm{dm}^{-3}$; $[\text { Substrate }]_{\mathrm{o}}=1.0$ $\times 10^{-3} \mathrm{~mol} \mathrm{dm}^{-3}$; and $[\mathrm{NaOH}]=4.4 \times 10^{-3} \mathrm{~mol} \mathrm{dm}^{-3}$.

Rate law (9) is in good agreement with the experimentally observed unit orders each in $[\mathrm{CAT}]_{\mathrm{o}}$ and $[\mathrm{S}]_{\mathrm{o}}$ and also fractional-order in $\left[\mathrm{OH}^{-}\right]$.

3.12. Calculation of Reaction Constants. Since rate $=$ $k^{\prime}[\mathrm{CAT}]_{\mathrm{t}}$, under pseudo first-order conditions of $[\mathrm{CAT}]_{\mathrm{o}}$ $<<<[]_{0},(9)$ can be transformed as follows:

$$
\begin{gathered}
k^{\prime}=\frac{K_{1} k_{2}[\mathrm{~S}]\left[\mathrm{OH}^{-}\right]}{\left[\mathrm{H}_{2} \mathrm{O}\right]+K_{1}\left[\mathrm{OH}^{-}\right]}, \\
\frac{1}{k^{\prime}}=\frac{\left[\mathrm{H}_{2} \mathrm{O}\right]}{K_{1} k_{2}[\mathrm{~S}]\left[\mathrm{OH}^{-}\right]}+\frac{1}{k_{2}[\mathrm{~S}]} .
\end{gathered}
$$

Based on (11), plots of $1 / k^{\prime}$ versus $1 /\left[\mathrm{OH}^{-}\right]$were linear $\left(R^{2}>0.9898\right)$ in all the three cases. From the slopes and the intercepts of these plots, equilibrium constant $\left(K_{1}\right)$ and decomposition constant $\left(k_{2}\right)$ were found to be $6.43 \times 10^{6}$, $5.29 \times 10^{6}$, and $6.72 \times 10^{6}$ and $0.08 \times 10^{-3}, 0.2 \times 10^{-3}$, and $0.3 \times$ $10^{-3} \mathrm{~s}^{-1}$ for CEX, CFL, and CPD, respectively. The proposed scheme and the derived rate law are also substantiated by the experimental observations discussed below.

3.13. Proton Inventory Studies. The proposed mechanism is supported by the increase in the rate of reaction in $\mathrm{D}_{2} \mathrm{O}$ medium which implies [21] a fast preequilibrium hydroxyl ion transfer (Step (i) of Scheme 1). For a reaction involving a fast equilibrium $\mathrm{H}^{+}$or $\mathrm{OH}^{-}$ion transfer, the rate increases in $\mathrm{D}_{2} \mathrm{O}$ since $\mathrm{D}_{3} \mathrm{O}^{+}$and $\mathrm{OD}^{-}$ions are stronger acid and stronger base (2 3 times greater), respectively, than $\mathrm{H}_{3} \mathrm{O}^{+}$ and $\mathrm{OH}^{-}$ions $[21,22]$. The increase of reaction rate with $\mathrm{D}_{2} \mathrm{O}$ in the present case and the obtained solvent isotope effect $k^{\prime}\left(\mathrm{H}_{2} \mathrm{O}\right)^{\prime} k^{\prime}\left(\mathrm{D}_{2} \mathrm{O}\right)<1$ conform to the above theory. The magnitude of isotope effect, however, is small, which can be attributed to the fractional-order dependence of rate on $\left[\mathrm{OH}^{-}\right]$.

Further, the proton inventory studies could shed some light on the nature of the transition state. The variation of rate 
(i) $\mathrm{TSNHCl}+\mathrm{OH}^{-} \underset{\text { Fast }}{\stackrel{K_{1}}{\rightleftharpoons}} \mathrm{TsN}^{-} \mathrm{Cl}+\mathrm{H}_{2} \mathrm{O}$

(ii)<smiles>[R]C(=O)N[C@H]1C(=O)N2C(C(=O)O)=C(C)CS[C@H]12</smiles><smiles>CC[C@H]1CC(C)=C(C(=O)O)N2C(=O)[C@H](NC(C)=O)[C@H]2C1</smiles><smiles>[R]C(=O)N[C@@H]1C(=O)N2C(C(=O)O)=C(C)CS(O)(Cl)C12</smiles><smiles>[R]C(=O)N[C@@H]1C(=O)N2C(C(=O)O)=C(C)CS(Cl)(Cl)C12</smiles><smiles>[R]C(=O)N[C@@H]1C(=O)N2C(C(=O)O)=C(C)CS(=O)[C@H]12</smiles>

(iii)<smiles>[R]C(=O)NC1C(=O)N2C(C(=O)O)=C(C)CS(=O)C12</smiles>

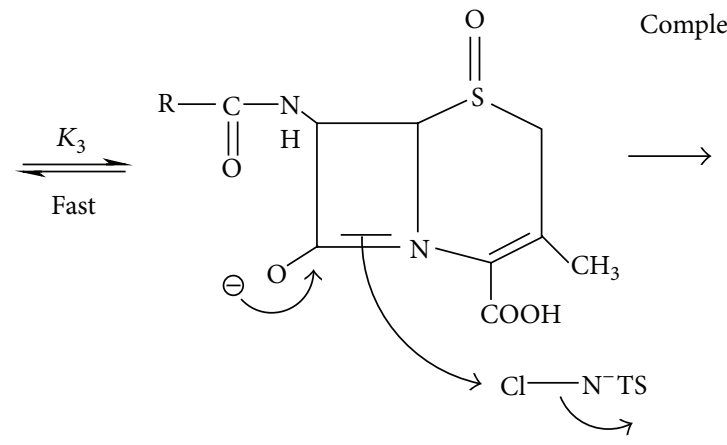

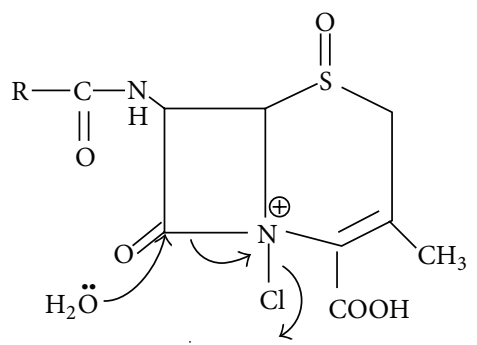<smiles>CC(C)C</smiles><smiles>[R]C(=O)NC(C(=O)O)C1NC(C(=O)O)=C(C)CS1=O</smiles>

SCHEME 2: A detailed mechanistic interpretation for the oxidation of cephalosporin drugs with CAT in alkaline medium.

constant for a reaction with the atom fraction of deuterium $(n)$ in mixtures of $\mathrm{H}_{2} \mathrm{O}$ and $\mathrm{D}_{2} \mathrm{O}$ is given $[23,24]$ by

$$
\frac{k_{o}^{\prime}}{k_{n}^{\prime}}=\frac{\prod^{\mathrm{TS}}\left(1-n+n \varphi_{i}\right)}{\prod^{\mathrm{RS}}\left(1-n+n \varphi_{j}\right)} .
$$

Here, $k_{n}^{\prime}$ is the rate constant in a mixed solvent which contains an atom fraction " $n$ " of deuterium, and $k_{o}^{\prime}$ is the rate constant in pure $\mathrm{H}_{2} \mathrm{O} . \varphi_{i}$ and $\varphi_{j}$ are the isotopic fractionation factors for isotopically exchangeable hydrogenic sites in the transition state (TS) and reactant states (RS), respectively. Equation (12) allows the calculation of the fractionation factor of TS if the reactant fractionation factor is known.

Proton inventory plot of $k_{n}^{\prime}$ versus $n$ (Figure $4 ; R^{2}=$ 0.9948; Table 3) in the present case is a straight line. A comparison with the standard plots [25] clearly indicates the involvement of a $\mathrm{OH}^{-}$ion or $\mathrm{OH}-\mathrm{D}$ exchanges during the reaction sequence. A linear plot is indicative of a simple solvent isotope effect involving single exchangeable hydroxyl ion in the transition state, which is isotopically distinct from water. Hence, the participation of $\mathrm{OH}^{-}$ion in the formation of transition state is inferred. Furthermore, if it is assumed that the reaction proceeds through a single transition state, (12) can be transformed into (13):

$$
\left(\frac{k_{o}^{\prime}}{k_{n}^{\prime}}\right)^{1 / 2}=\left[1+n\left(\varphi_{j}-1\right)\right] .
$$

Equation (13) indicates a linear relation between $\left(k_{o}^{\prime} / k_{n}^{\prime}\right)^{1 / 2}$ and $n$ which is shown in (Figure $\left.4 ; R^{2}=0.9948\right)$. The slope $\left(\varphi_{j}-1\right)=-0.29$, from which the fractionation factor $n$ is found to be 0.71 . Kresge and Allred [26] obtained 


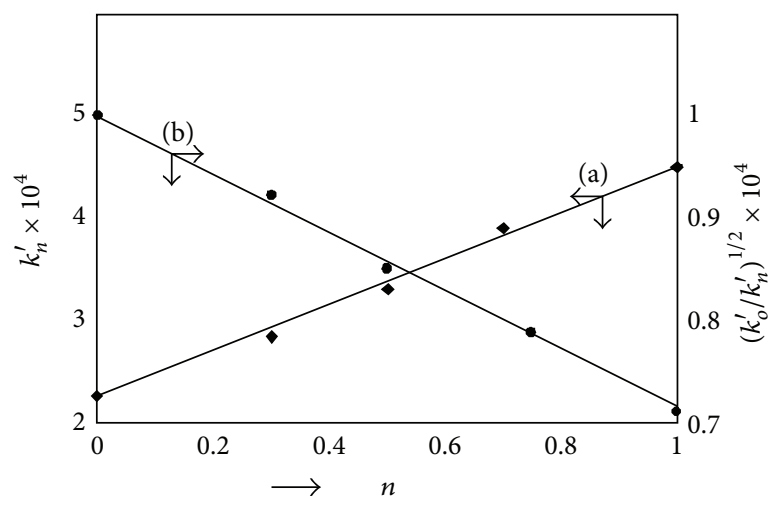

FIGURE 4: Proton inventory plots of (a) $k_{n}^{\prime}$ versus $n$ and (b) $\left(k_{o}^{\prime} / k_{n}^{\prime}\right)^{1 / 2}$ versus $n$. Experimental conditions are as in Table 3.

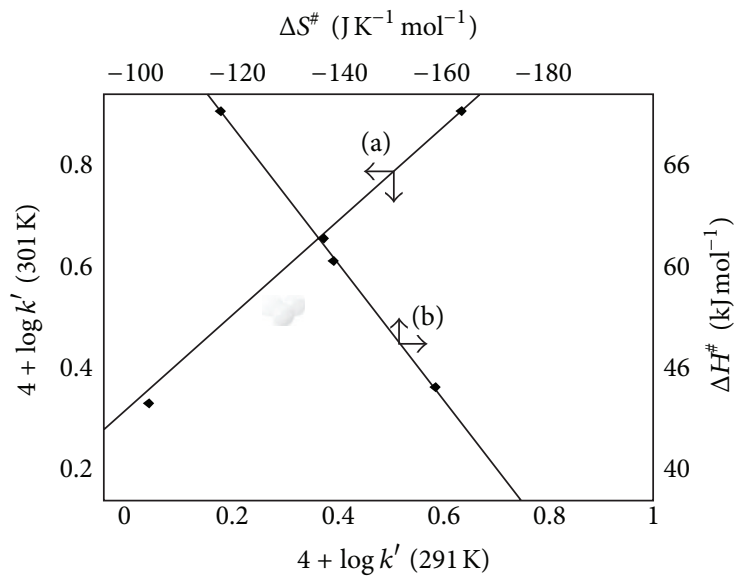

Figure 5: Isokinetic plots of (a) $\Delta S^{\#}$ versus $\Delta H^{\#}$ and (b) $\log k_{(291 \mathrm{~K})}^{\prime}$ versus $\log k_{(301 \mathrm{~K})}^{\prime}$. Experimental conditions are as in Table 4.

a value of 0.80 through NMR studies for the isotopic fractionation factor of $\mathrm{OH}^{-}$, which is confirmed by Gold and Grist [27]. Considering the diversity of procedures employed, there is an agreement between the present value and the values reported in the literature.

3.14. Dielectric Constant Effect. The effect of changing solvent composition on the rate of a bimolecular reaction has been discussed by Kirkwood [28]. The theory of Kirkwood was further developed by Laidler and Landskroener [29] and Tanford and Kirkwood [30]. A good account of these and other theories has been given by Entelis and Tiger [31]. Further, for the limiting case of zero angle approach between two dipoles or an ion-dipole system, Amis [32] has shown that a plot of $\log k^{\prime}$ versus $1 / D$ gives a straight line with a negative slope for the reaction between a negative ion and a dipole or between the dipoles, while a positive slope results in a positive-ion dipole interaction. The negative dielectric effect
TABLE 4: Effect of varying temperature on the rate of reaction and activation parameters for the oxidation of cephalosporins by CAT in alkaline medium.

\begin{tabular}{lccc}
\hline Temperature (K) & \multicolumn{3}{c}{$10^{4} k^{\prime}\left(\mathrm{s}^{-1}\right)$} \\
& CEX & CFL & CPD \\
\hline 291 & 1.10 & 2.82 & 4.79 \\
296 & 1.61 & 4.16 & 6.46 \\
301 & 2.31 & 5.15 & 9.84 \\
306 & 3.80 & 7.90 & 14.5 \\
$E_{a}\left(\mathrm{~kJ} \mathrm{~mol}^{-1}\right)$ & 61.3 & 53.6 & 46.7 \\
$\Delta H^{\#}\left(\mathrm{~kJ} \mathrm{~mol}^{-1}\right)$ & 58.8 & 51.2 & 44.3 \\
$\Delta G^{\#}\left(\mathrm{~kJ} \mathrm{~mol}^{-1}\right)$ & 94.3 & 92.2 & 90.8 \\
$\Delta S^{\#}\left(\mathrm{JK}^{-1} \mathrm{~mol}^{-1}\right)$ & -119 & -137 & -156 \\
$\log A$ & 11.3 & 10.4 & 9.4 \\
\hline
\end{tabular}

Experimental conditions: $[\mathrm{CAT}]_{\mathrm{o}}=2.0 \times 10^{-4} \mathrm{~mol} \mathrm{dm}^{-3} ;$ Substrate $_{\mathrm{o}}=1.0$ $\times 10^{-3} \mathrm{~mol} \mathrm{dm}^{-3}$; and $[\mathrm{NaOH}]=4.4 \times 10^{-3} \mathrm{~mol} \mathrm{dm}^{-3}$.

observed in the present studies (Table 2) clearly supports the negative ion-dipole nature of the rds in the proposed scheme.

3.15. Ionic Strength Effect. The proposed reaction mechanism is also evinced by the observed zero effect of ionic strength on the rate of reaction. The primary salt effect on the reaction rates has been described by Brønsted and Bjerrum theory [33]. According to this concept, the effect of ionic strength $(\mu)$ on the rate of a reaction involving two ions is given by the following relationship:

$$
\log k^{\prime}=\log k_{o}^{\prime}+1.02 Z_{A} Z_{B} \mu^{1 / 2},
$$

where $A$ and $B$ are the reacting ions, $Z_{A}$ and $Z_{B}$ are the charges on the respective species, $k^{\prime}$ and $k_{o}^{\prime}$ are the rate constants in the presence and in the absence of the added electrolyte, respectively. Equation (14) shows that a plot of $\log k^{\prime}$ versus $\mu^{1 / 2}$ would be linear yielding a slope $1.02 Z_{A} Z_{B}$ and an intercept $\log k_{o}^{\prime}$. As the slope of the line depends on charges of the reacting ions, three special cases may arise: (i) if $A$ and $B$ have the same charges, $Z_{A} Z_{B}$ will be positive and the rate constant $k^{\prime}$ increases with $\sqrt{\mu}$; (ii) if $A$ and $B$ have opposite signs, $Z_{A} Z_{B}$ will be negative and the rate constant $k^{\prime}$ decreases with $\sqrt{\mu}$; and (iii) if either $A$ or $B$ is uncharged, $Z_{A} Z_{B}$ is equal to zero and $k^{\prime}$ is independent of the ionic strength of the solution. In the present case, a negative charge and a neutral molecule are involved in the rate-determining step (Step (ii) of Scheme 2). Hence, variation of the ionic strength of the medium does not alter the rate, and it clearly conforms to the above theory (case (iii)).

3.16. Isokinetic Relationship. Variation in rate within a reaction series may be caused by changes in both enthalpy of activation $\left(\Delta H^{\#}\right)$ and entropy of activation $\left(\Delta S^{\#}\right)$, but these quantities vary in a parallel fashion. These variables are correlated by a linear relationship: $\Delta H^{\#}=\Delta H_{o}^{\#}+\beta \Delta S^{\#}$, where $\beta$ is the isokinetic temperature. It is the temperature at which the rate constant is identical for the reaction series. Table 4 shows that the activation energy is the highest for the slowest reaction and vice-versa, indicating that the reaction 


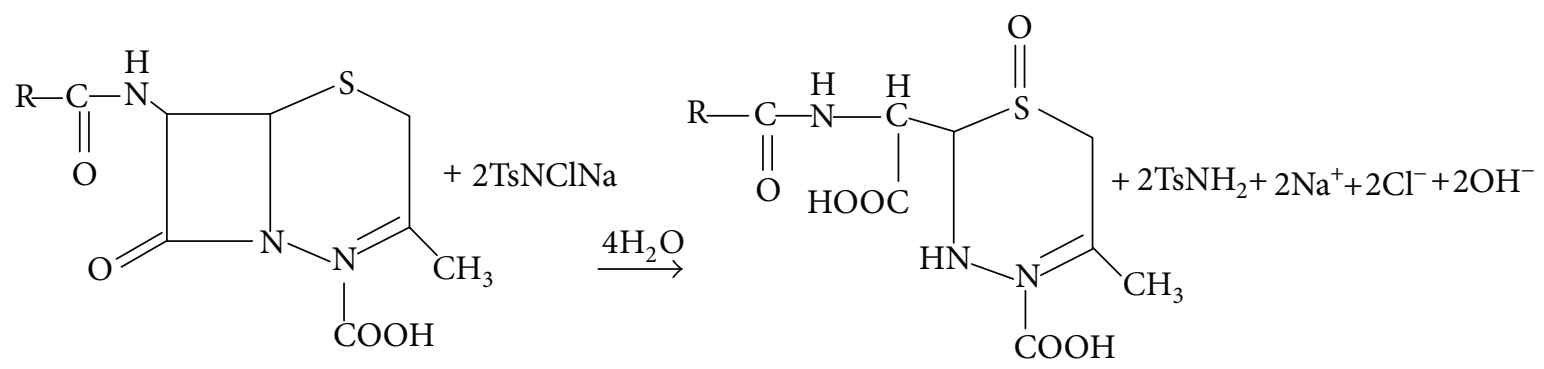

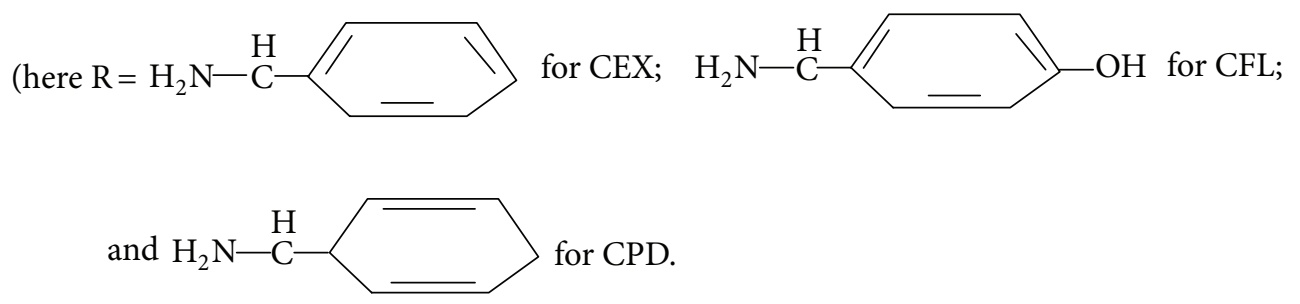

FIGURE 6

is enthalpy controlled. This is verified by calculating the isokinetic temperature $(\beta)$ from the slope of linear plot of $\Delta H^{\#}$ versus $\Delta S^{\#}$ (Figure $5 ; R^{2}=0.9990$ ). The value of $\beta$ was found to be $378 \mathrm{~K}$. Further, the validity of isokinetic relation has been done by the Exner criterion [34] by plotting $\log k_{(301 \mathrm{~K})}^{\prime}$ versus $\log k_{(291 \mathrm{~K})}^{\prime}$, which gives a straight line (Figure $5 ; R^{2}=0.9913$ ). The value of $\beta$ was calculated from the equation $\beta=T_{1} T_{2}(q-1) /\left(q T_{2}-T_{1}\right)$, where $q$ is the slope of the Exner plot; $\beta$ was found to be $370 \mathrm{~K}$.

Generally, in a chemical reaction, when there is a formation of a molecular complex or a linear relationship exhibits between enthalpy, and entropy one might observe what is known as enthalpy-entropy compensation. This can be expressed as

$$
\Delta H^{\#}=a \Delta S^{\#}+b,
$$

where $a$ and $b$ are constants, usually called as compensation parameters. This type of compensation has been observed in various processes, and many models have been put forward to explain this complex phenomenon [35, 36]. According to the transition state theory, the rate constant of the reaction which gives the product from the activated reaction is given as

$$
k=\frac{k_{B} T}{h} \exp \left(\frac{\Delta S^{\#}}{R}\right) \exp \left(\frac{-\Delta H^{\#}}{R T}\right)
$$

which can be rewritten as follows:

$$
\begin{gathered}
\left(R T \ln k_{B} \frac{T}{h}\right)-R T \ln k=\Delta H^{\#}-T \Delta S^{\#}, \\
\Delta H^{\#}=\beta \Delta S^{\#}-R \beta \ln \left(\frac{k h}{k_{B} \beta}\right) .
\end{gathered}
$$

By comparing (15) and (18),

$$
a=\beta, \quad b=R \beta \ln \left(\frac{k h}{k_{B} \beta}\right) .
$$

The enthalpy-entropy compensation points out that the variations of $\Delta \mathrm{H}^{\#}$ in (18) are compensated by variations in $\Delta \mathrm{S}^{\#}$.

When the experimental temperature $T<\beta$, the reaction rate or equilibrium is mainly by the enthalpy change. In this region, the reaction with the lowest activation energy will react fast, and the interpretation involved in potential energy surfaces can be made. At temperatures above $\beta$, however, the controlling factor is $\delta \Delta \mathrm{S}^{\#}$, and interpretations based upon potential energy surfaces would obviously be in error. In general, it is found that the electronic effects are contained in the enthalpy factor and that many solvent effects are due to the entropy factor. Activation energy is the highest for the slowest reaction and vice-versa (Table 4), and the value of $\beta$ obtained is higher than the experimental temperature, which clearly indicates that the reaction is enthalpy controlled in the present case. This result also implies that the family of reactions proceeds through same mechanistic pathways.

3.17. Relative Reactivity of the Substrates. From the rate data (Table 4), the rate of oxidation of cephalosporins was found to follow the order cephradine $>$ cefadroxil $>$ cephalexin. This trend can be explained as in Figure 7.

In Structure I (cephradine), there is no $\pi$ cloud interaction with lone pair of electrons of sulphur atom of the substrate, which makes the sulphur atom more reactive to undergo oxidation at a faster rate. The Structure II (cefadroxil) might get converted into quinonoid forms (IIa) or (IIb) which results in less reactivity towards sulphur, and hence the rate of oxidation is slower than cephradine. In 


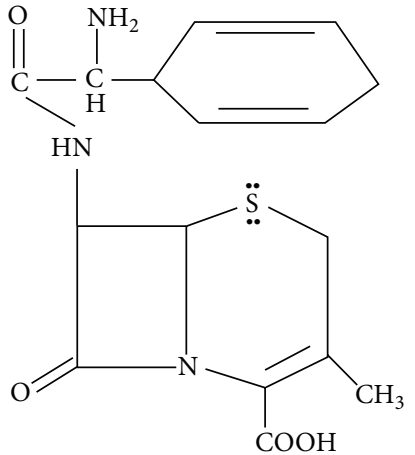

Structure I (cephradine)

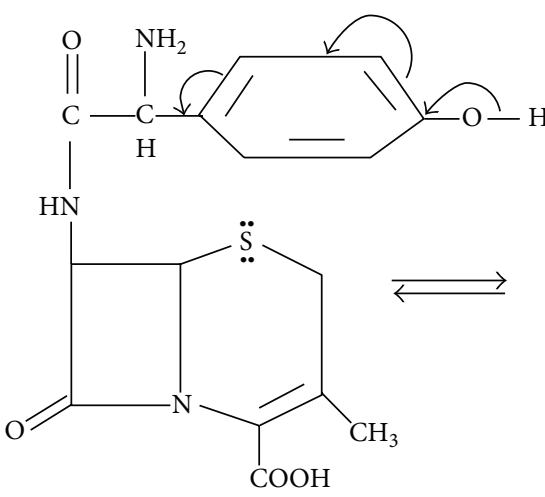

Structure II (cefadroxil)

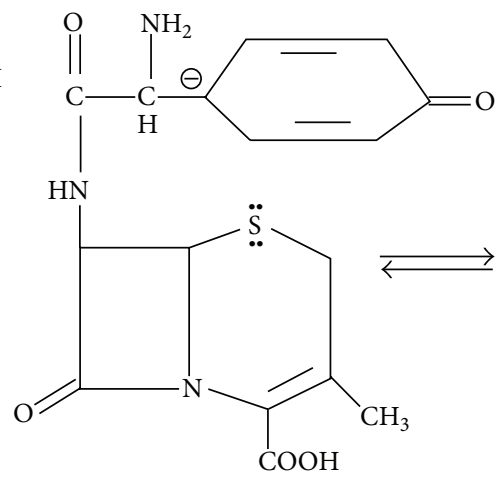

Structure (II a)

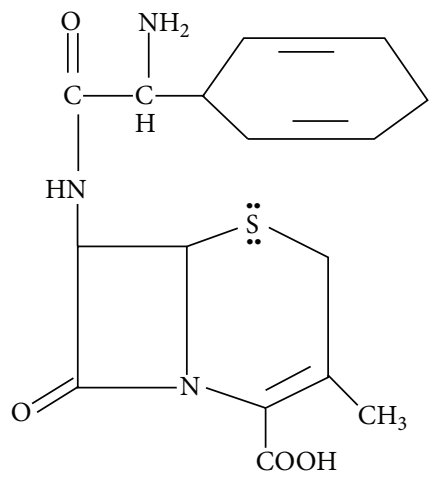

Structure III (cephalexin)

Structure (II b)

FIGURE 7

Structure III (cephalexin), there is an involvement of $\pi$ cloud of the arene with lone pair of electrons of sulphur atom making it less reactive towards the oxidant. Hence, the rate of oxidation of cephalexin is the least when compared to cephradine (Structure I) and cefadroxil (Structure II).

3.18. Activation Parameters. The proposed mechanism is also supported by the moderate values of energy of activation and other thermodynamic parameters. The large negative values of $\Delta S^{\#}$ indicate the formation of a more ordered, rigid associative transition state in each case. The high positive values of free energy of activation indicate that the transition state is highly solvated. The near constancy of $\Delta \mathrm{G}^{\#}$ shows the operation of an identical mechanism in the oxidation of all the three substrates of the present study.

\section{Conclusions}

Based on the experimental results, the following conclusive remarks can be acquired.

Oxidation of all three drugs follows identical kinetics with a rate law: Rate $=k^{\prime}[\mathrm{CAT}][\mathrm{S}]\left[\mathrm{OH}^{-}\right]^{x}$, and here, $x<1$. From the inspection of rate data, the rate of oxidation of drugs follows the order: cephradine $>$ cefadroxil $>$ cephalexin.
The stoichiometry of the reaction was found to be $1: 2$, and oxidation products were confirmed by mass spectral analysis. Activation parameters and isokinetic temperature indicates that the reaction is enthalpy controlled, and all the three drugs react with CAT via the same mechanism. A suitable scheme and relevant rate law have been worked out.

\section{Conflict of Interests}

The author hereby declare that they do not have any direct financial relation with the commercial identity mentioned in the paper.

\section{Acknowledgments}

The authors thank VGST, Department of Science and Technology, Government of Karnataka, India, for the CESEM award Grant no. 24, 2010-2011. they also thank Professor M. A. Pasha for his valuable suggestions about the schemes.

\section{References}

[1] L. A. Mitscher, "Antibiotics," in Principles of Medical Chemistry, W. O. Foye, Ed., pp. 759-762, Lea and Febiger, Philadelphia, Pa, USA, 5-8th edition, 1995. 
[2] G. A. Saleh, S. R. El-Shaboury, F. A. Mohamed, and A. H. Rageh, "Kinetic spectrophotometric determination of certain cephalosporins using oxidized quercetin reagent," Journal of Pharmaceutical and Biomedical Analysis, vol. 45, pp. 1-19, 2007.

[3] J. G. Hardaman, L. E. Limbird, and A. G. Gilman, Goodman Gilman's-The Pharmacological Basic of Therapeutics, McGrawHill, New York, NY, USA, 9th edition, 1995.

[4] G. A. Saleh, H. F. Askal, I. A. Darwish, and A. N. A. El-Shorbagi, "Spectroscopic analytical study for the charge-transfer complexation of certain cephalosporins with chloranilic acid," Analytical Sciences, vol. 19, no. 2, pp. 281-287, 2003.

[5] M. M. Ayad, A. A. Shalaby, H. E. Abdellatef, and H. M. Elsaid, "Spectrophotometric determination of certain cephalosporins through oxidation with cerium(IV) and 1-chlorobenzotriazole," Journal of Pharmaceutical and Biomedical Analysis, vol. 20, no. 3, pp. 557-564, 1999.

[6] E. Bishop and V. J. Jennings, "Titrimetric analysis with chloramine-T-I. The status of chloramine-T as a titrimetric reagent," Talanta, vol. 1, no. 3, pp. 197-212, 1958.

[7] A. R. V. Murthy and B. S. Rao, "Oxidation by chloramine-T. Part II. Redox potential of chloramine-T-sulfonamide systems," Proceedings of the Indian Academy of Science, vol. 35, pp. 69-72, 1952.

[8] G. Agnihothri, "Chloramine-T (Sodium N-Chloro-p-toluenesulfonamide)," Synlett, vol. 18, pp. 2857-2858, 2005.

[9] M. M. Campbell and G. Johnson, "Chloramine T and related Nhalogeno-N-metallo reagents," Chemical Reviews, vol. 78, no. 1, pp. $65-79,1978$.

[10] K. K. Banerji, B. Jayaram, and D. S. Mahadevappa, "Mechanistic aspects of oxidation by N-metallo N-haloarylsulfonamides," Journal of Scientific \& Industrial Research, vol. 146, pp. 65-76, 1987.

[11] E. Kolvari, A. Ghorbani-Choghamarani, P. Salehi, F. Shirini, and M. A. Zolfigol, "Application of N-halo reagents in organic synthesis," Journal of the Iranian Chemical Society, vol. 4, no. 2, pp. 126-174, 2007.

[12] K. S. Rangappa, K. Manujunathaswamy, M. P. Ragavendra, and N. M. M. Gowda, "Kinetics and mechanism of oxidation of neutral -amino acids by sodium N-chloro-p-toluenesulfonamide in acid medium," International Journal of Chemical Kinetics, vol. 34, no. 1, pp. 49-57, 2002.

[13] R. V. Jagadeesh and P. Puttaswamy, "Ru(III), Os(VIII), Pd(II) and Pt(IV) catalysed oxidation of glycyl-glycine by sodium $\mathrm{N}$ chloro-p-toluenesulfonamide: comparative mechanistic aspects and kinetic modelling," Journal of Physical Organic Chemistry, vol. 21, no. 10, pp. 844-858, 2008.

[14] P. Puttaswamy, A. Sukhdev, and J. P. Shubha, "Palladium(II)catalyzed oxidation of tranexamic acid by bromamine-B in alkaline medium and uncatalyzed reaction in acid medium: a study of kinetic and mechanistic chemistry," Journal of Molecular Catalysis A: Chemical, vol. 332, no. 1-2, pp. 113-121, 2010.

[15] K. N. Vinod, P. Puttaswamy, and K. N. Ninge Gowda, "Os(VIII) as an efficient homogeneous catalyst for the oxidative decolorization of methylene blue dye with alkaline chloramine$\mathrm{T}$ : kinetic, mechanistic, and platinum metal ions reactivity studies," Industrial and Engineering Chemistry Research, vol. 49, no. 7, pp. 3137-3145, 2010.

[16] J. Carrell Morris, J. Alfredo Salazar, and M. A. Wineman, "Equilibrium studies on N-chloro compounds. I. The ionization constant of N-chloro-p-toluenesulfonamide," Journal of the American Chemical Society, vol. 70, no. 6, pp. 2036-2041, 1948.
[17] G. Akerloff, "Dielectric contents of some organic solvent-water mixtures at various Temperatures," Journal of the Chemical Society, vol. 54, pp. 4125-4139, 1932.

[18] F. F. Hardy and J. P. Johnston, "The interactions of Nbromo-N-sodiumbenzenesulfonamide(bromamine-B) with $\mathrm{p}$ nitrophenoxide ion," Journal of the Chemical Society, Perkin Transactions, vol. 2, pp. 742-750, 1973.

[19] T. Higuchi and J. Hasegawa, "Rate exchange of chlorine between dimethylchloramine and succinamide," The Journal of Physical Chemistry, vol. 69, pp. 796-799, 1965.

[20] B. G. Pryde and F. D. Soper, "The direct interchange of chlorine in the interaction of $\mathrm{p}$-toluenesulfonamide and N-chloroacetanilide," Journal of the Chemical Society, pp. 1510-1512, 1931.

[21] C. J. Collins and N. S. Bowman, Isotope Effects in Chemical Reactions, Van-Nostrand, New York, NY, USA, 1970.

[22] A. Kohen and H. H. Limbach, Isotope Effects in Chemistry and Biology, CRC Press, Boca Raton, Fla, USA, 2006.

[23] W. J. Albery and M. H. Davies, "Mechanistic conclusions from the curvature of solvent isotope effects," Journal of the Chemical Society, Faraday Transactions, vol. 68, pp. 167-181, 1972.

[24] G. Gopalakrishnan and J. L. Hogg, "Kinetic and mechanistic studies of the N-bromosuccinimide-promoted oxidative decarboxylation of glycine, DL-alanine, and DL-valine," The Journal of Organic Chemistry, vol. 50, pp. 1206-1212, 1985.

[25] N. S. Isaccs, Physical Organic Chemistry, John Wiley \& Sons, New York, NY, USA, 1987.

[26] A. J. Kresge and A. L. Allred, "Hydrogen isotope fractionation in acidified solutions of protium and deuterium oxide," Journal of the American Chemical Society, vol. 85, pp. 1541-1547, 1963.

[27] V. Gold and S. Grist, "Deuterium solvent isotope effects on reactions involving the aqueous hydroxide ion," Journal of the Chemical Society, Perkin Transactions, vol. 2, pp. 89-95, 1972.

[28] J. Kirkwood, "Dispersion and Absorption in Dielectrics I. Alternating Current Characteristics," Journal of Chemical Physics, vol. 2, p. 2351, 1934.

[29] K. J. Laidler and P. A. Landskroener, "The influence of the solvent on reaction rates," Transactions of the Faraday Society, vol. 52, pp. 200-210, 1956.

[30] C. Tanford and J. G. Kirkwood, "Theory of protein titration curves. I. General equations for impenetrable spheres," Journal of the American Chemical Society, vol. 79, no. 20, pp. 5333-5339, 1957.

[31] S. G. Entelis and R. P. Tiger, Reaction Kinetics in the Liquid Phase, John Wiley \& Sons, New York, NY, USA, 1976.

[32] E. S. Amis, Solvent Effects on Reaction Rates and Mechanisms, Academic Press, New York, NY, USA, 1955.

[33] K. J. Laidler, Chemical Kinetics, Tata Mc Graw-Hill, New Delhi, India, 1995.

[34] O. Exner, "On the enthalpy—entropy relationship," Collection of Czechoslovak Chemical Communications, vol. 29, pp. 1094-1113, 1964.

[35] E. B. Starikov and B. Nordén, "Enthalpy-entropy compensation: a phantom or something useful?" Journal of Physical Chemistry B, vol. 111, no. 51, pp. 14431-14435, 2007.

[36] P. C. Moyano and R. N. Zúñiga, "Enthalpy-entropy compensation for browning of potato strips during deep-fat frying," Journal of Food Engineering, vol. 63, no. 1, pp. 57-62, 2004. 

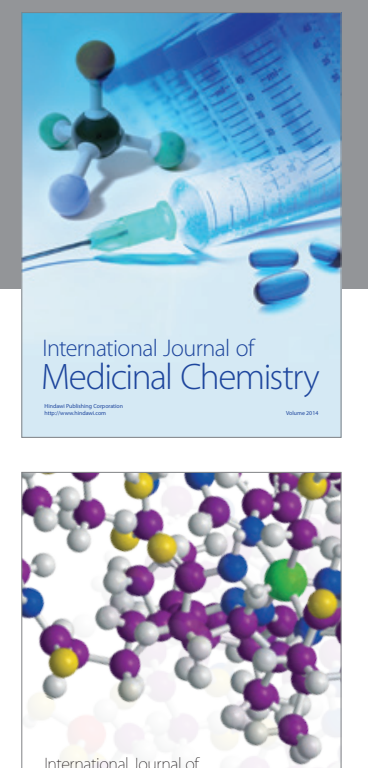

\section{Carbohydrate} Chemistry

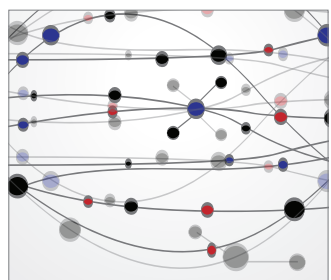

The Scientific World Journal
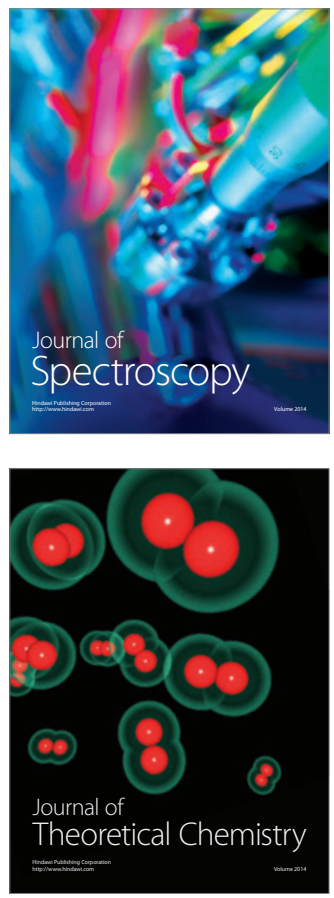
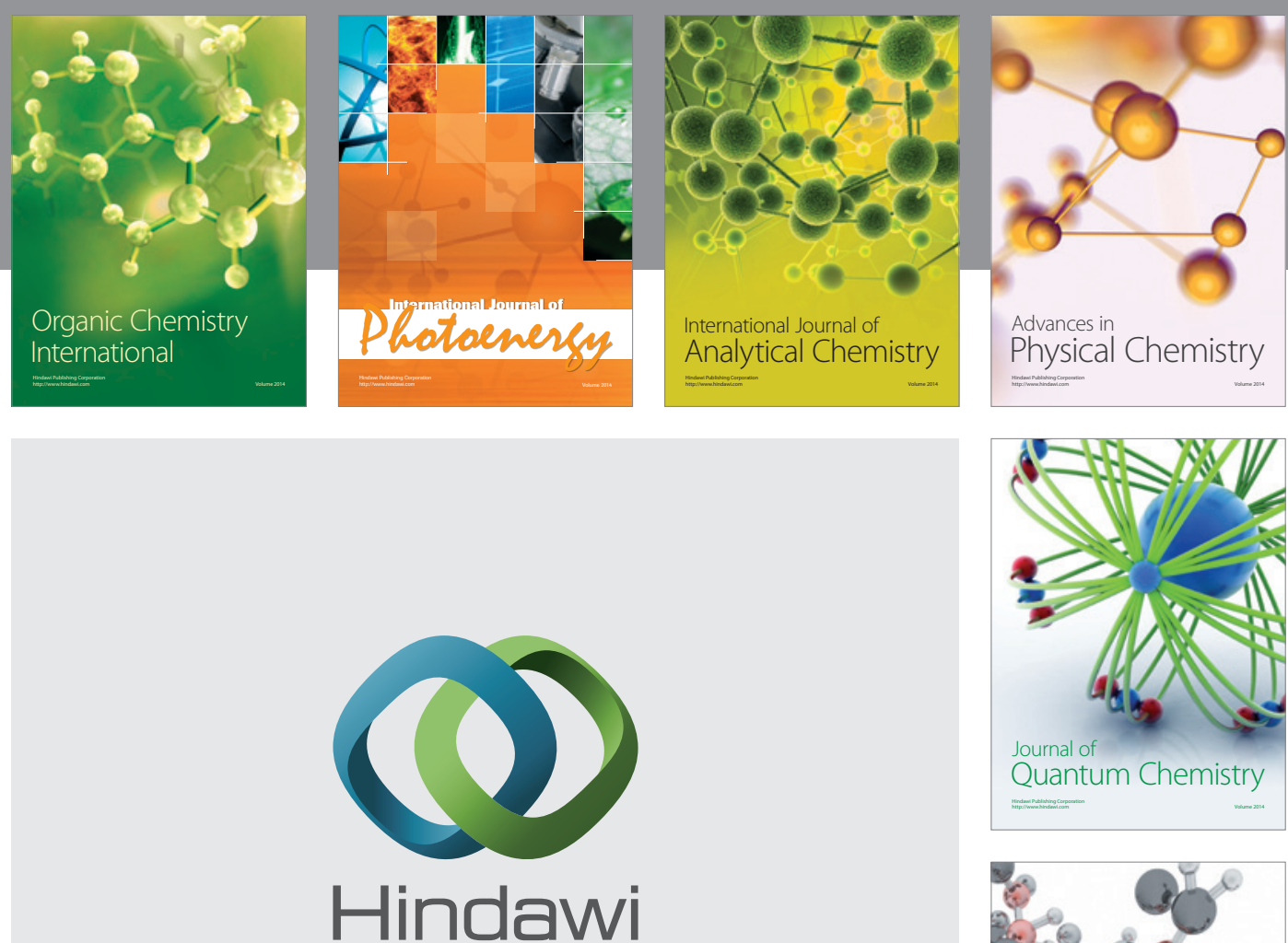

Submit your manuscripts at

http://www.hindawi.com

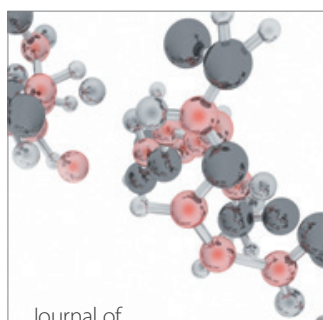

Analytical Methods

in Chemistry

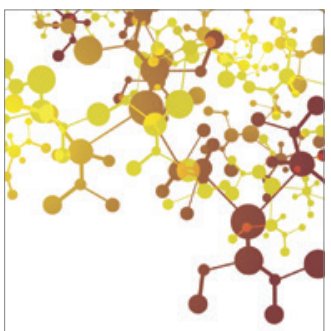

Journal of

Applied Chemistry

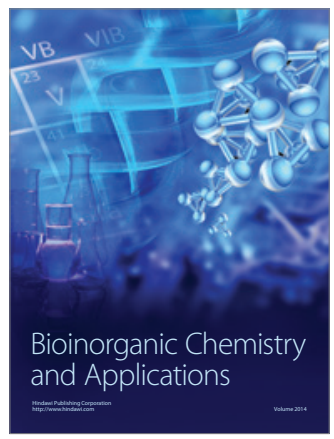

Inorganic Chemistry
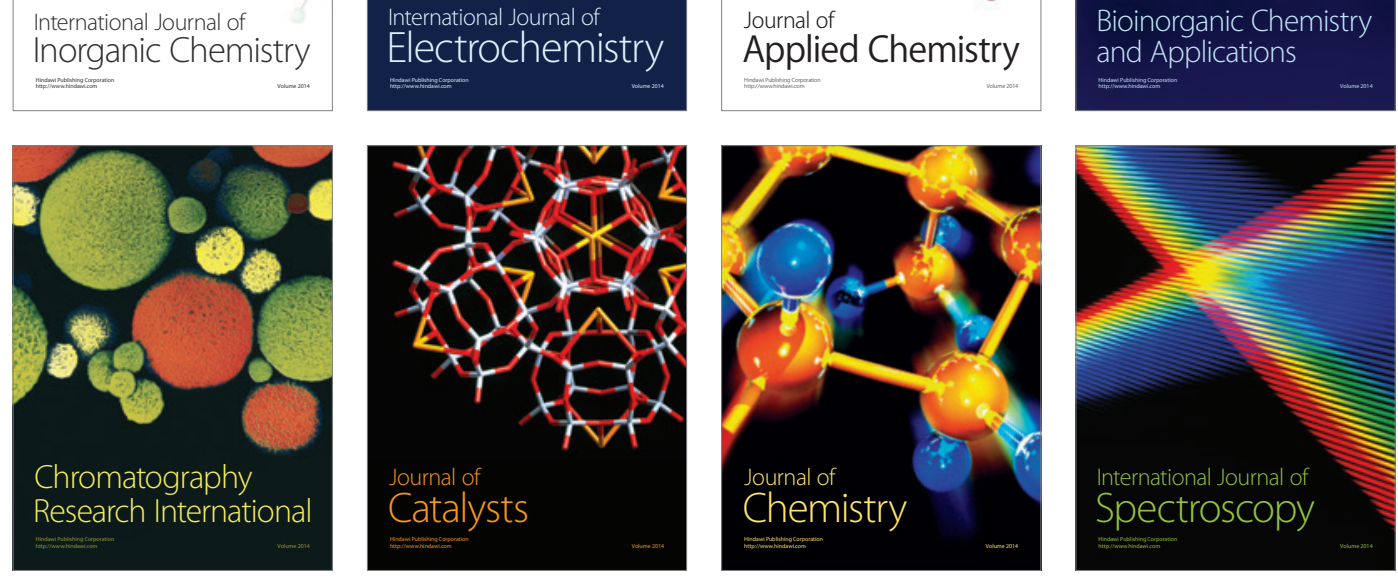